\title{
I. On liquid diffusion
}

\section{J.J. Coleman F.I.C. F.C.S. F.R.S.E.}

To cite this article: J.J. Coleman F.I.C. F.C.S. F.R.S.E. (1887) I. On liquid diffusion, Philosophical Magazine Series 5, 23:140, 1-10, DOI: $10.1080 / 14786448708627973$

To link to this article: http://dx.doi.org/10.1080/14786448708627973

\section{曲 Published online: 29 Apr 2009.}

Submit your article to this journal $\pi$

LII Article views: 3

Q View related articles 두 
LONDON, EDINBURGH, AND DUBLIN

\title{
PHILOSOPHICAL MAGAZINE
}

\author{
AND \\ JOURNAL OF SCIENCE.
}

[FIFTH SERIES.]

$J A N U A R Y 1887$.

I. On Liquid Diffusion.

By J. J. Coleman, F.I.C., F.C.S., F.R.S.E.*

[Plate I.]

UR knowledge upon this subject is chiefly derived from Graham's classical researches. His first paper was communicated to the Royal Society in 1849, and further papers in 1850 and 1851.

About the year 1855, Fick $\dagger$, commenting upon these investigations, remarked that it was a matter of regret that in such an exceedingly valuable and extensive investigation the development of a fundamental law for diffusion in a single element of space was neglected, which (he added) it was quite natural to suppose would be identical with the law according to which diffusion of heat takes place in a conducting body, and upon which Fourier founded his theory of heat, and $\mathrm{Ohm}$ his theory of diffusion of electricity in conductors. Fick endeavoured to supply this omission so far as common salt is concerned, and Voit calculated the coefficient of diffusion of sugar. Professor Mach, of Prague, has also worked with these substances. Other experimenters have calculated the coefficients of diffusion of salts, or, rather, of a limited number of them, with not very concordant results, as may be seen by consulting the tables of Schumeister attached to the article "Heat," by Sir W. Thomson, in the ninth edition of the Encyclopecdia Britannica, and comparing them with the results of Beilstein, who employed Jolly's method, described in

* Communicated by the Author.

+ Phil. Mag. [4] x. 1855.

Phil. Mag. S. 5. Vol. 23. No. 140. Jan. 1887. 
Watts's 'Dictionary of Chemistry,' vol. iii. p. 710. Graham, however, in his latest paper upon the subject, communicated to the Royal Society in 1861, described a method of experiment which, to use his own words, affords a means of obtaining the absolute rate or velocity of diffusion. This he called "Jar diffusion," the saline solution being delivered by a pipette to the bottom of a column of pure water 127 millim. high, standing in a cylindrical jar 87 millim. diameter, and the amount diffused being ascertained by drawing off the liquid from the top in equal fractions by a very fine syphon, the orifice of the short leg of which was kept close under the surface of the liquid being drawn off.

Graham applied this method to a variety of organic compounds, but only to hydrochloric acid, sulphate of magnesia, and sulphates and chlorides of potassium and sodium amongst inorganic substances. He did not attempt the calculation of the coefficients of diffusibility in absolute measurements, but remarked that the method is extremely simple, and gives results of more precision than could have been possibly anticipated.

I have recently made a considerable number of experiments with this method; but in place of using jars of 87 millim. in diameter I have employed glass cylinders of $36 \mathrm{millim}$. diameter, such as are used for "Nesslerizing," and which are very uniform in bore. The annexed Table shows the actual amount of salt found in each section of the liquid after diffusion, expressed in millimetres; the quantity of salt in the upper section being also calculated in percentages of that particular section which at the commencement of the diffusion was the point of junction of the saline solution and the pure water.

The concentrated saline solution was introduced below the pure water by a method slightly different to that of Graham; namely, a fine-bore syphon with contracted orifices was first filled with water, the finger being placed so as to cover the short end ; the long end was thrust to the bottom of the water in the diffusion-jar, and the short end was uncovered in a vessel containing the saline solution at a higher level, and the syphoning continued until the height of the liquid admitted under the water in the diffusion-jar amounted to 50 millim.

Many of the results agree with those of Graham, whilst others are additions thereto, such as the diffusions of mercurous nitrate, mercuric chloride, lithium sulphate, cadmium sulphate, silver sulphate, manganese sulphate, nickel sulphate, and lead nitrate.

Moreover they are twenty-five diffusions conducted for equal lengths of time; and under similar circumstances as to temperature and methods of experimenting. 
Graham's Jar Diffusion Method.

Diffusions for 14 days, at an average temperature of $12^{\circ} \cdot 5 \mathrm{C}$.

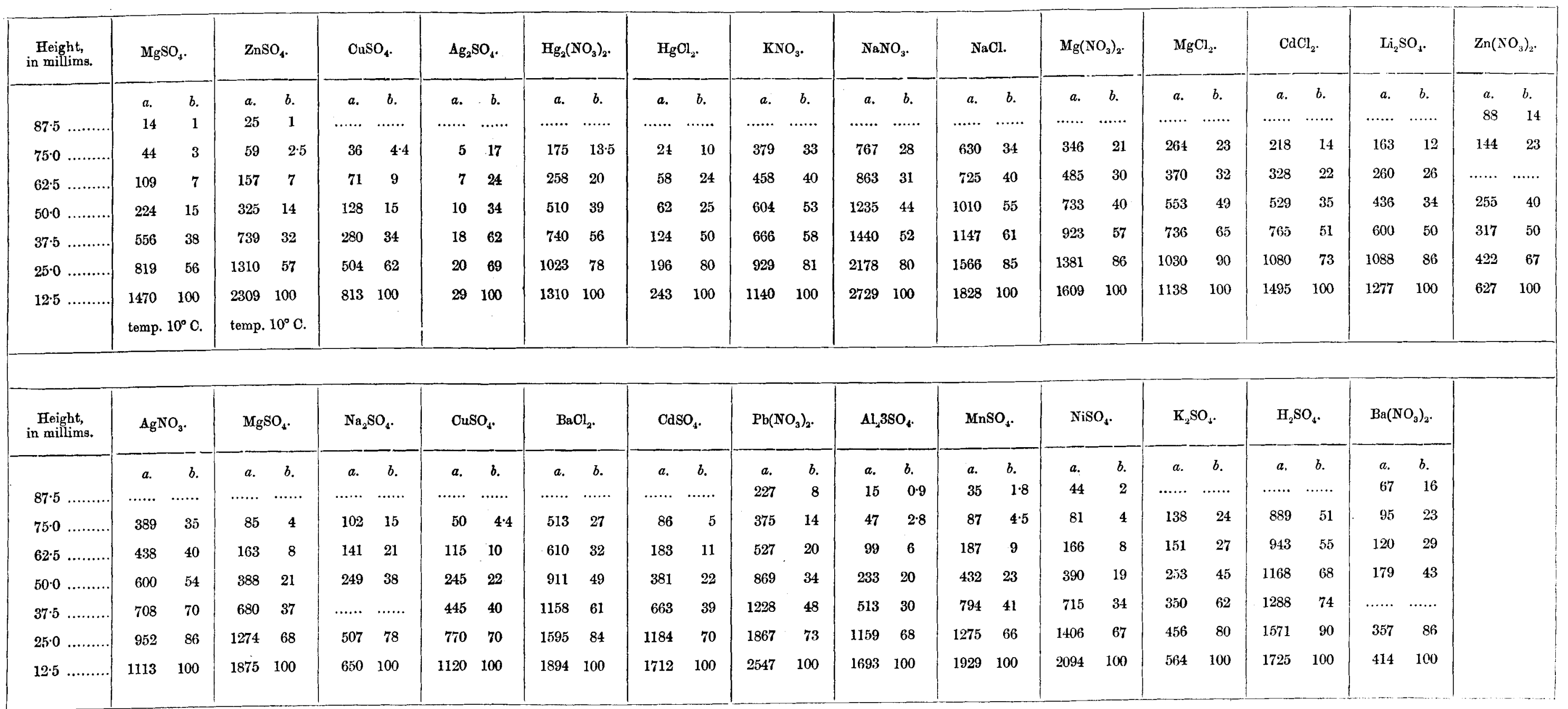

NorE. - Column (a) gives the weight in milligrams of salt in each section syphoned off fron the top.

Column (b) gives the approximate percentage of weight, assuming the bottom layer to contain 100 of salt. 
Although from many points of view, and especially that of the chemist, most valuable and important deductions can be made from this class of experiments, some of which will be referred to in a later part of this paper, it must be admitted that, from the physicist's point of view, all these experiments are vitiated from the fact that the diffusions should commence with the solid salt or the anhydrous acid or alkali, and end in an atmosphere of pure water. With Graham's earlier experiments a saline or acid solution, the strength of which was gradually diminishing, was diffused into a weaker saline or acid solution which was constantly increasing ; and even with his latest method of "Jar diffusion" it is practically impossible to work with syphons in long columns of water such as are necessary to get a pure water atmosphere above, the salt being diffused. I have therefore tarned my attention to improved methods of working, and have devised apparatus, illustrated by Plate I. fig. 1*. This apparatus allows of a very concentrated solution of the substance under examination being admitted at any desired rate of speed underneath a column of pure water of any desired length, and, further, of the liquids being drawn off in regulated quantities at the end of the time of diffusion. No doubt, with solid crystalline salts, theory indicates that diffusion should commence from the salt; but practice determines the fact that, with solid salts, air-bubbles are a difficulty; and, moreover, there are a very large number of salts that are not crystalline at all, and some that do not exist in the solid state, such as $\mathrm{MgCl}_{2}$.

Returning to the description of fig. 1, B B represents a Mohr's burette 500 millim. long and 15 millim. diameter provided with a glass stopcoek.

The stopcock being closed, this burette is nearly filled with pure water, and is then connected by india-rubber tubing with an apparatus by means of which the air above the water can be slightly rarefied, such as an air-pump or an aspirator, or, by what I find most convenient, an open glass tube $\mathrm{CO}$ standing in a jar of water. On opening the stopcock of the burette, about half its water escapes, say, to the level $(a)$ (rarefying the air above), upon which a column of water rushes up the tube $\mathrm{CC}$, say to $x$. The stopcock being now closed, the tabe $\mathrm{CC}$ is raised and clipped in such a position that the column of water in the tabe $\mathrm{CC}$ is much longer than the water-column in the burette, by which means the air above the water in the burette is sufficiently rarefied to admit of the concentrated saline or other solution being sucked up

* A description of this apparatus and the principal results detriled in this paper were communicated to the Philasophical Society of Glasgow, 16 th April, 1886. 


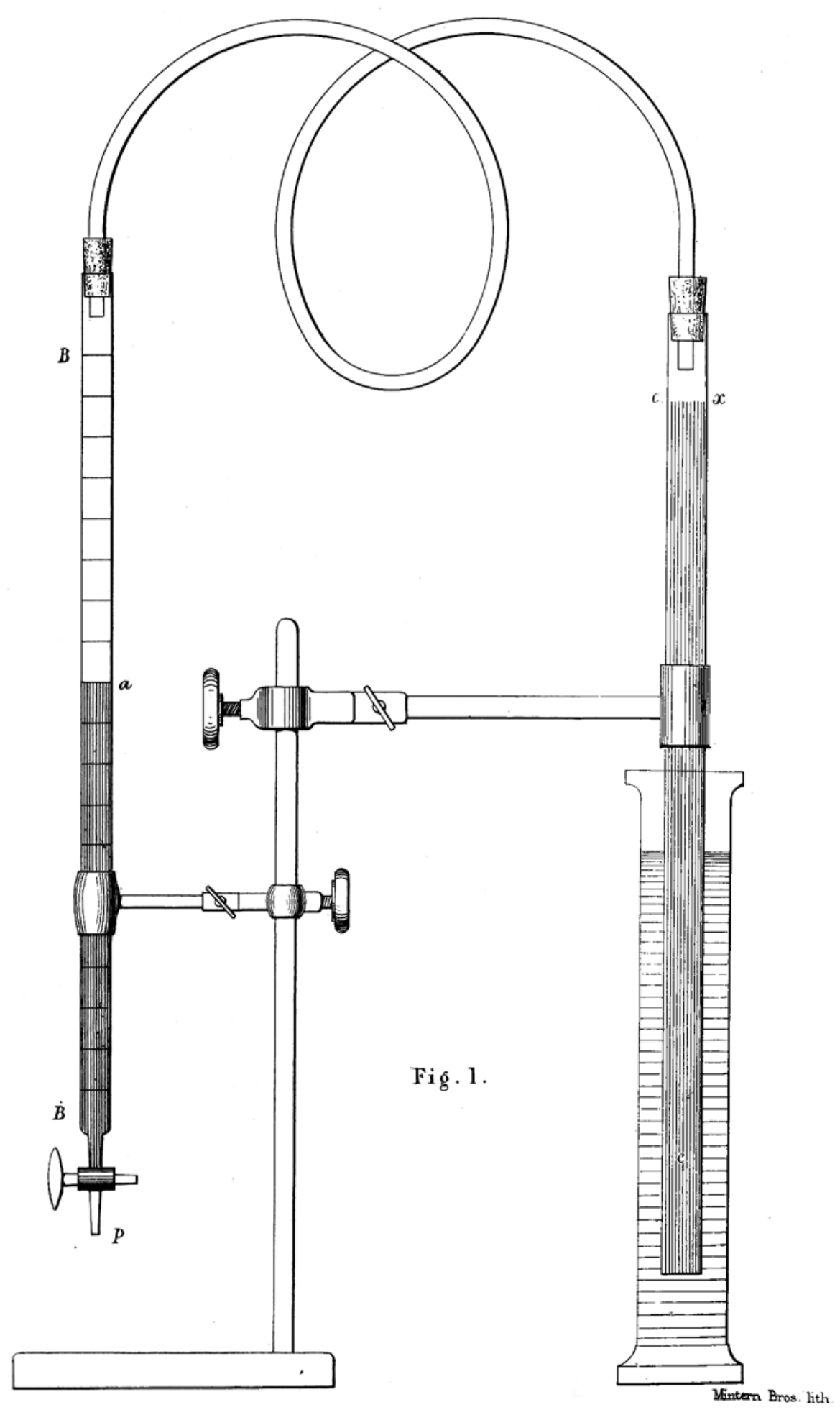

Phil. Mag. S.5.Vol. 23 . Pl.I.
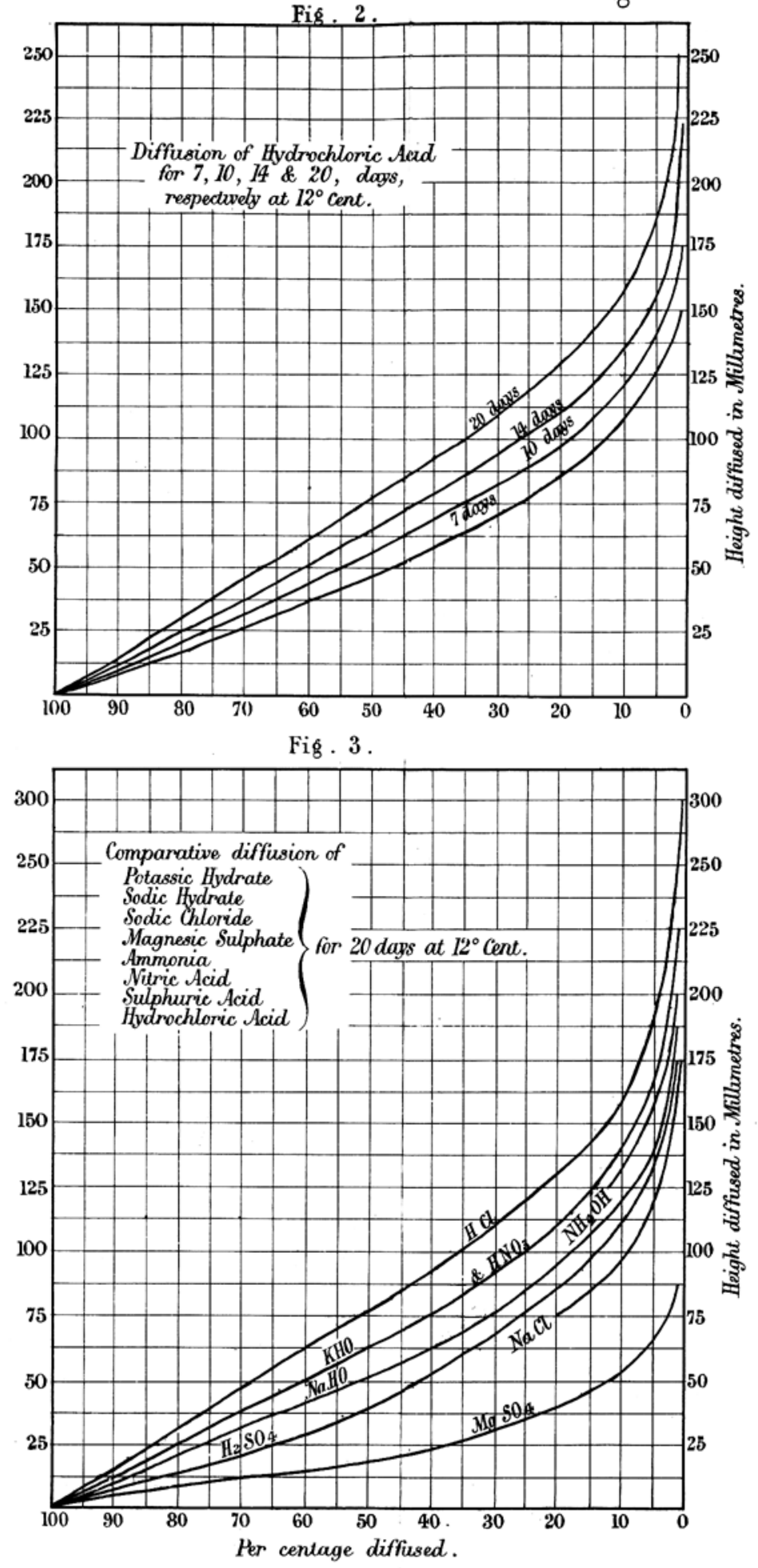
underneath the water by cautiously opening the stopcock. A column, say, 100 millim. deep can be drawn into the burette under a depth of water of 200 millim., which latter can be further added to by filling up the burette cautiously by a longlegged pipette discharged on a cork float. This, however, is seldom necessary except with very diffusive substances, such as hydrochloric acid, which barely reach a height of 200 millim. in 21 days. To prevent leakages, an indiarubber cap is slipped over the point $p$ of the burette. At the end of the diffusion-time the liquid is very slowly run off until the level where the water originally joined the saline solution is reached, after which equally-measured sections are carefully removed and reserved for further examination, each section being, say, 25 millim. deep. The results are conveniently calculated in percentages upon the salt or other substance contained in the bottommost layer, where diffusion commenced. It was thought at first that some errors might arise from adberence of the saline solutions to the inside of the burette, down which the upper layers had to pass before estimation. This proved, however, not to be the case to any serious or appreciable extent. Most diffusions are carried on until at any rate 1 per cent. of the salt rises 50 millim.; and it was found that sulphuric acid of 1.2 specific gravity, admitted in the burette under water coloured blue with litmus and then withdrawn carefully, had so little effect on the water 25 millim. above that it came out of the stopcock barely reddened, and the water lying 50 millim. above the acid came out quite blue. Corroborative experiments were made with saturated cupric sulphate and ammonia as an indicator.

Hydrochloric acid being the most diffusive substance examined by Graham, comparative experiments were made with this compound at temperatures of $12^{\circ} .5$ Centigrade, the results of which are shown in the curves, fig. 2.

Fig. 3 shows in the form of curves the results of some comparative experiments made for a period of twenty days at a temperature of $12^{\circ} .5 \mathrm{C}$, with the following substances:-

1. Sulphuric acid containing 20 per cent. anhydride.

2. Hydrochloric acid " 20

3. Nitric acid

4. Potassic hydrate

5. Sodic hydrate

$20 \quad "$ "

" 20 " "

" 20 " "

6. Ammonia solution of $" 880$ specific "gravity.

7. Magnesic sulphate . saturated.

8. Sodic chloride . . . ditto.

The ammonia solution was floated on the water, the rest admitted under the water, and, with the exception of the 
Mr. J. J. Coleman on Liquid Diffusion.

magnesic sulphate, the sections of liquid run off were estimated by ordinary volumetric alkalimeter processes.

A summary of the results may be conveniently added :-

Comparative diffusion during twenty days ; temperature $12^{\circ} \cdot 5$ Cent.

One per cent. of the hydrochloric acid rose 250 millim.

\begin{tabular}{|c|c|c|c|c|}
\hline ", & $"$ & nitric acid & $"$ & 225 \\
\hline , & " & potassic bydrate & $"$ & 225 \\
\hline 14 & " & ammmonia & " & 200 \\
\hline " & $"$ & sulphuric acid & $"$ & 175 \\
\hline " & $"$ & sodic hydrate & $"$ & 187 \\
\hline$\eta$ & $"$ & sodic chloride & " & 162 \\
\hline & , & magnesic sulphate & י & 87 \\
\hline
\end{tabular}

These results are put forward merely as preliminary experiments with a method which is rapid in execution and susceptible of great accuracy, and which it is hoped will afford or lead to the means of calculating the correct coefficient of diffusion of a large number of substances, Sir W. Thomson having kindly promised his assistance in any mathematical calculations necessary.

From the chemist's point of view, several interesting considerations arise from a review of experiments already made, particularly when taken in connection with Newland's and Mendelejeff's periodic law, which was not put forward until some time after the date of Graham's last paper.

The periodic law classifies the elements into vertical groups of the type $\mathrm{R}_{2} \mathrm{O}$, RO, \&c., and into series usually known as horizontal series. Most of our recent textbooks quote the 3rd series as typical ; thus :-

$\begin{array}{ccccccc}\text { Na. } & \text { Mg. } & \text { Al. } & \text { Si. } & \text { P. } & \text { S. } & \text { Cl. } \\ \text { Atomic weight . 23 } & 24 & 27 \cdot 3 & 28 & 31 & 32 & 35 \cdot 5 \\ \text { Atomic volume , 24 } & 14 & 10 & 11 & 14 \cdot 5 & 16 & 27\end{array}$

It will be observed here that whilst there is a comparatively small difference between the atomic weights commencing and ending the horizontal series, the atomic volume commences very high at the extreme left, gradually diminishes to less than one half in the middle, and ends very high again at the extreme right of the series. Diffusibility of the compounds of these elements varies in the same way; thus :-

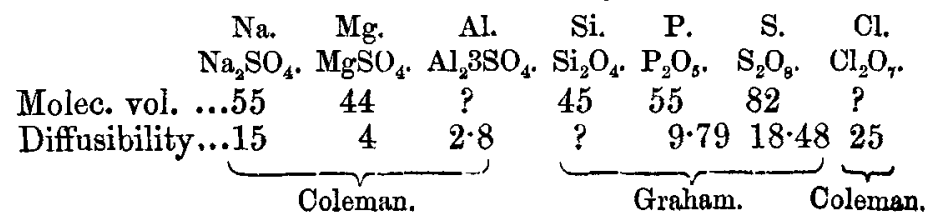


The diffusion of chloric acid against sulphuric acid I had to make specially*; the other figures are from the tables and data before given, and the atomic volumes are quoted from Ira Remsen's recent book, the 'Principles of Theoretical Chemistry.'

Here then is evidence that, given a number of elements the atomic weights of which do not differ widely, the diffusibility will vary in some sort of proportion to the atomic or molecular volume, which latter, indeed, may be to some extent regulated by the energy of the molecules.

Mendelejeff's fourth horizontal series commences with $K$ and $\mathrm{Ca}$, the molecular volumes and diffusibilities of the chlorides being thus :-

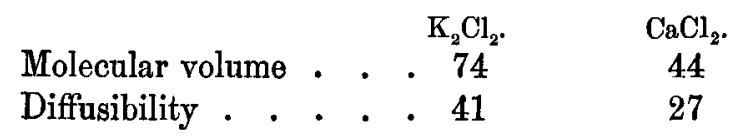

Here again diffusibility corresponds with the larger molecular volume.

The fifth series commences with copper and zinc, the molecular volume of the sulphates being exactly equal and the diffusibility nearly equal.

The sixth series commences with rubidium and strontium, the metal rubidium possessing, with the exception of cæsium, the largest atomic volume of any metal yet discovered.

Graham has already shown that chloride of strontium is much less diffusible than chloride of potassium. If, therefore, chloride of rubidium be as diffusible as chloride of potassium, then the diffusibility of chloride of rubidium will be greater than that of chloride of strontium. This has been proved to be the case by the following diffusions I have recently made. Chloride of rubidium, chloride of potassium, and chloride of sodium were diffused for 10 days at $12^{\circ} \mathrm{C}$. in the apparatus figured on Plate I.

* By new method of diffusion :-

58 per cent. sulphuric acid rose 25 millim. in 7 days.

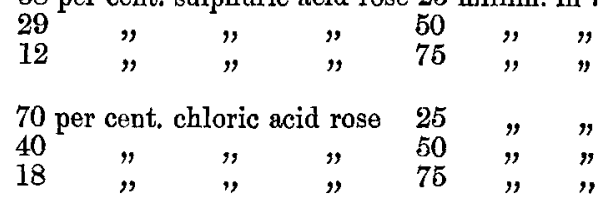

temperature $12^{\circ}$ Cent. 


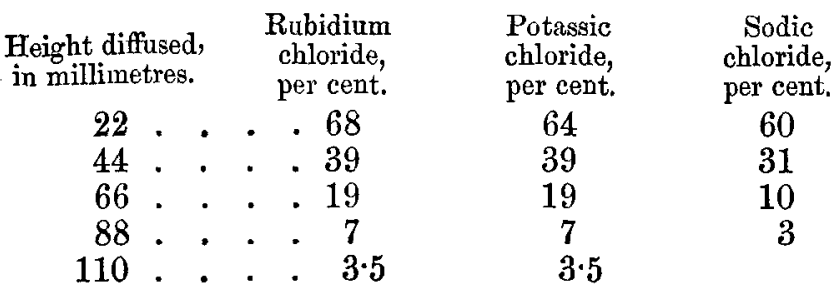

It will be seen that rubidium chloride is quite as diffusive as potassic chloride, a salt which has hitherto been the most diffusive salt examined. This I anticipated from the large atomic volume of the metal, which is very much greater than even that of potassium; but, on the other hand, its atomic weight is greater.

If a large molecular volume indicates a tendency to rapidity of diffusion, it may be suspected that a large atomic or molecular weight has a tendency to retard it; this, however, is not so easy to prove, from the extreme difficulty of getting groups of soluble compounds, the molecular volumes of which are identical, but the molecular weights of which differ. Moreover, it appears necessary to look for such groups in the family groups of Mendelejeff's vertical series, or the isomorphous groups of the older chemists. The sulphates of zinc and magnesia are strictly isomorphous, and possess an identical molecular volume, viz. 44 when anhydrons, their molecular weights being as 120 to 161 .

Graham not only in this case, but in several other cases of isomorphous bodies, strove hard to prove that the rate of diffusion was identical, returning again and again to the subject, on the last occasion making seventy-two experiments with magnesic and zincic sulphates; which he sums up by stating that the approach to equality becomes close in the 4-per-cent. and larger portions of salt, but differed as much as 8.75 per cent. in favour of the sulphate of magnesia in the 1-per-cent. solutions.

I have recently diffused these substances for the long period of 50 days, and at a temperature of $15^{\circ} \mathrm{C}$., in the apparatus described in an earlier part of this paper as an improvement upon Graham's. The results are that-

9 per cent. of the magnesic sulphate rose 100 millim.

It therefore appears that these substances are not equidiffusive, and that the one possessing the least molecular weight is the most diffusive. These experiments are very 
decisive also on the matter of solubility not influencing diffusibility, since the sulphate of zinc is well known to be much more soluble in water than the sulphate of magnesia.

Two substances from Mendelejeff's 6th group, viz. chromic acid and tungstic acid, were selected for diffusion; the molecular volumes of which are identical, and the molecular weights of which are as 100.5 to 232 . They were diffused as normal salts of soda for thirty days, at a temperature of $12^{\circ} .5 \mathrm{C}$., with this result (in which it will be again observed the one possessing the least atomic weight is most diffusive):-

25 per cent. of chromate of soda rose 75 millim.

17 " tungstate " 75 "

Molybdate of soda was diffused also at the same time, but as the atomic volume of molybdic acid is not identical but larger than that of either of the other two, there was a greater diffusibility, viz. :-

28 per cent. molybdate of soda rose 75 millim.

In the case of Mendelejeff's 7th group we have chlorides, bromides, and iodides of the following molecular weights and volumes:-

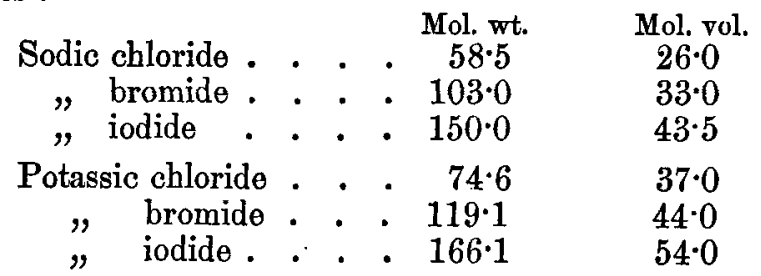

In all these cases it will be noticed that there is an increase of molecular volume simultaneous with an increase of molecular weight, so that it is possible retardation of diffusibility, owing to an increased molecular weight, may be counterbalanced by an increased energy, indicated by the larger molecular volume; and may account for the singular fact discovered by Graham that these substances are practically equally diffusive, though further experiment may show some little variations. Similar remarks may be made in regard to the chlorides and nitrates of calcium, strontium, and barium, which Graham also showed to be practically equally diffusive.

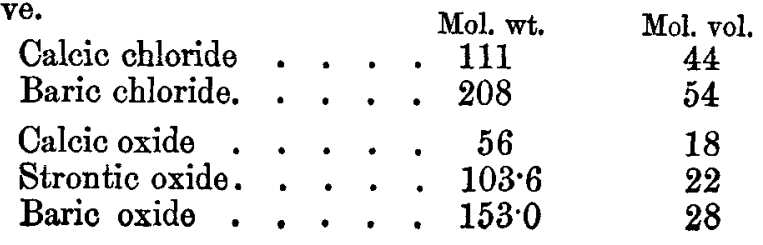


In regard to Mendelejeff's 8th group, I have diffused ferrous sulphate, cobaltous sulphate, nickelous sulphate, and cupric sulphate, the molecular weights and volumes of which are as follows :-

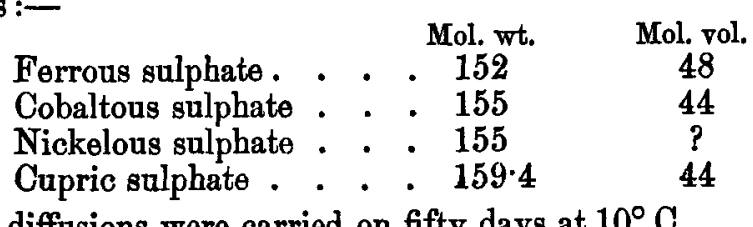

The diffusions were carried on fifty days at $10^{\circ} \mathrm{C}$.

11 per cent. of the iron rose 100 millim.

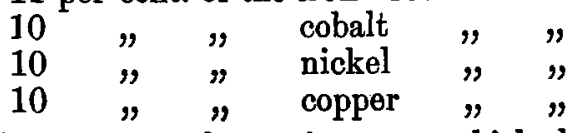

The diffusion rate of these substances, which closely approximates those of Mendelejeff's 2nd group, the Dyads, also corroborates the other experience as to the influence of the molecular weights and volumes.

The difference in diffusibility, however, between the first, or Monad group of Mendelejeff, and his second, or Dyad group, is very striking, and can be approximately represented by the following figures:-

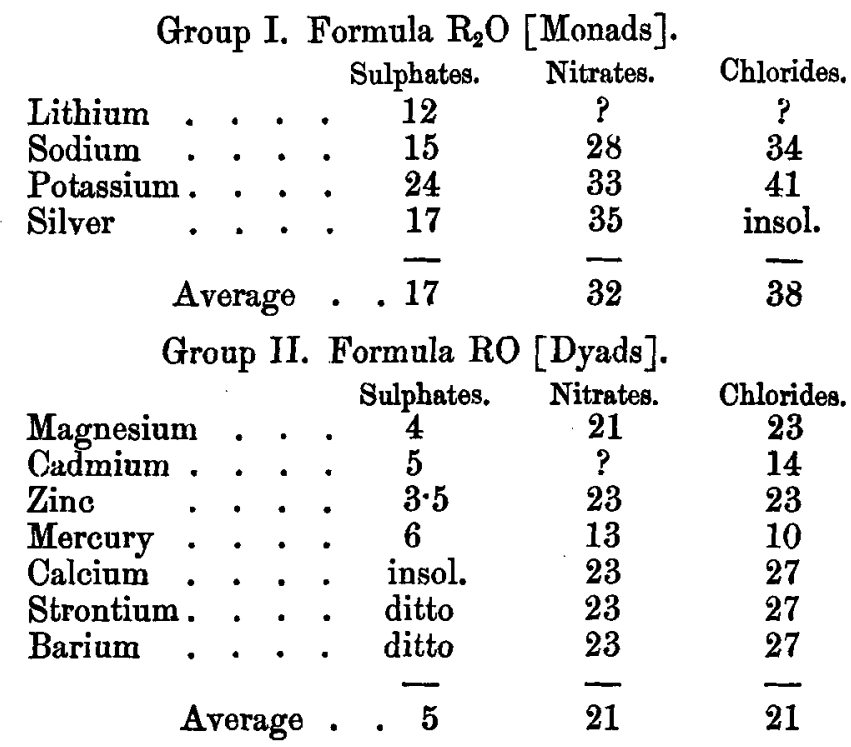

Mendelejeff classes cuprous salts with Monads; and it is singular that very early in his experiments Graham pointed 
out that cuprous chloride has only half the diffusibility of cupric chloride.

I am still prosecuting the investigation, and other interesting relationships may be detected, but the data as to the specific gravity and molecular volumes of compounds of many of the rarer elements are entirely wanting, and even in the case of those of well-known elements are incomplete.

\section{On the Self-induction of Wires.-Part V. $B y$ Oliver Heaviside*.}

THEE mathematical difficulties in the way of the discovery 1 of exact solutions of problems concerning the propagation of electromagnetic disturbances into wires of other than circular section-or, even if of circular section, when the return current is not equidistantly distributed as regards the wire, or is not so distant that its influence on the distribution of the wire current throughout its section may be disregarded -are very considerable. As soon as we depart from the simple type of magnetic field which occurs in the case of a straight wire of circular section, we require at least two geometrical variables in place of the one, distance from the axis of the wire, which served before; and we may have to supplement the magnetic force " of the current," as usually understood, by a polar force, or a force which is the space-variation of a single-valued scalar, the magnetic potential, in order to make up the real magnetic force.

There are, however, some simplified cases which can be fully solved, viz. when the external magnetic field, that in the dielectric, is abolished, by enclosing the wire in a sheath of infinite conductivity. It is true that we must practically separate the wire from the sheath by some thickness of dielectric, in order to be able to set up current in the circuit by means of impressed force, so that we cannot entirely abolish the external magnetic field; but we may approximate in a great measure to the state of things we want for purposes of investigation. The wire, of conrse, need not be a wire in the ordinary sense, but a large bar or prism. The electrostatic induction will be ignored, requiring the wire to be not of great length; thus making the problem an electromagnetic one.

Consider, then, a straight wire or rod or prism of any symmetrical form of section, so that when a uniformly distributed current passes through it its axis is the axis of the magnetic

* Communicated by the Author. 